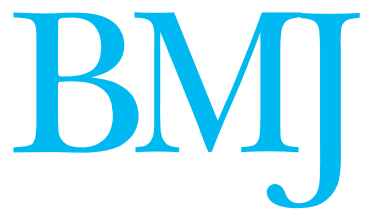

\title{
The future of health care in Africa
}

\author{
Depends on making commitments work in and outside Africa
}

$\mathrm{A}$

the group of eight leading industrialised nations (G8) meets for its summit at Gleneagles, Scotland, next week Africa is at a crossroads. It faces a double edged crisis: its healthcare workforce is rapidly depleting, and its health systems are weak, fragile, and hanging on a precipice. A direct consequence of this is that the indicators for health development in the continent are dismal. About one in six African children die before their fifth birthday, with half of these dying from diseases preventable by vaccines; and one woman dies every two minutes from complications of pregnancy and delivery. ${ }^{1}$ From all such indications and current evidence, it would appear that very few countries in the continent will achieve the millennium development goals. ${ }^{2}$ The goal to reduce deaths among children aged under 5 (figure) is just one example.

Chronic underinvestment, interventions by global partnerships that focus only on single diseases, and sporadic financing by both national governments and their partners have left African health systems prostrate. They are unable to deliver drugs, tools, and other interventions of proved effectiveness against the leading causes of early death and illness throughout the continent. The apparently unabating national and household poverty in Africa is widely debated, and yet, despite the substantial growth in the global economy over the past half century, most of Africa remains poor. The living conditions are not conducive to good

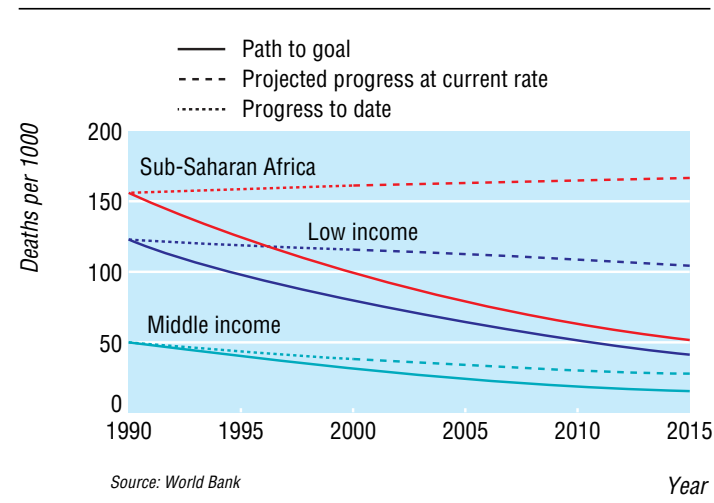

Progress in reducing mortality in children aged under 5 years, comparing sub-Saharan Africa with low and middle income countries in the rest of the world. Red represents sub-Saharan Africa, blue low income countries, green middle income countries (with solid lines indicating path to goal, dotted lines progress to date, and dashed lines projected progress at current rate) health, and people are without access to the inexpensive drugs and medicines that have proved efficacious and beneficial. ${ }^{3}$ The world can no longer ignore Africa and its people, and commitments to reverse this unacceptable trend are now at centre stage. Interventions in health policy will be just as important as efforts to move forward Africa's social and economic development agenda.

The diversity and complexity of healthcare systems in Africa mean that magic bullets or "one size fits all" approaches are doomed to fail. Such approaches have not achieved success and, anyway, cannot be sustained at the current fiscal capacity. Sustainable financing from national budgets and real increases in overseas development assistance to Africa are critical if the continent is to join the rest of the world in improving global health and continuing the marked fall in mortality among children since 1960 seen elsewhere.

There is strong evidence that Africa has risen to this challenge. The health strategy of the New Partnership for Africa's Development (NEPAD) outlines actions that are to be taken by African countries in the renewed spirit of partnership and collaboration. The strategy identifies key actions to strengthen health systems, improve partnership and communication with communities, and focus local action on the leading burdens in Africa-malaria, HIV/AIDS, and obstetric emergencies. African governments have signed up to the NEPAD health strategy, ${ }^{4}$ and increasingly governments are allocating at least $15 \%$ of their total budgets to health care in compliance with the Abuja target agreed in 2003.

The implementation of this commitment by African governments is being monitored closely by the African Union, and the union has called on the international community to fill the $\$ 19 \mathrm{bn}$ ( $£ 10 \mathrm{bn}$; $€ 16 \mathrm{bn})$ gap in health financing that the World Health Organization has determined that Africa is unable to self finance. ${ }^{6}$ The union is also making concerted efforts to expand the options for healthcare financing and to engage the private sector in innovative partnerships that can deliver basic healthcare services to African families and households. The Commission for Africa, consulting widely on health issues, heard the voice of the continent. It is not surprising, therefore, that the commission's report has much in common with the key regional strategies within Africa to improve health systems and outcomes. 
The report of the Commission for Africa has tried to chart the way forward, calling for an additional increase in overseas development assistance of up to \$25bn a year by 2010 , and a further investment of the same amount by 2015 , subject to a review of progress. The report provides bold and innovative targets to which members of the G8 and others are expected to commit at their summit this week. The report is labelled by some the Marshall plan for Africa, a reference to the European recovery programme followed by the United States for the reconstruction of Europe after the second world war and named after the former US secretary of state George Marshall.

The commission's report rightly identifies strengthened health systems, good governance, peace, and security as central to the efforts to stem Africa's downward spiral. It also acknowledges the importance of partnerships supporting pan-African institutions and regional organisations, and a framework that recognises the need for partners to respond to both regional and national priorities. The commission urges that immediate attention is given to the deficits in Africa's health workforce, information and management systems, and essential medicines and other health commodities; it also highlights the need for investments to follow the NEPAD health strategy and invest in regional institutions.

Health workers comprise the core of the healthcare system in Africa. Several groups have called on the G8 to invest in Africa's efforts to stem the brain drain and to produce the right multidisciplinary workforce to improve the performance of health systems and meet regional and global targets for health. Africa does not simply need more health workers; investments must also help to increase the motivation, retention, and accessibility of the workforce to make a real difference. Regional cooperation is crucial to solving the human resources crisis. This could include support for "brain sharing" between the nations in the region that produce health workers, such as South Africa and Nigeria; negotiation of expansion in fiscal space (the flexibility of financial management often restricted by conditions of loans and grants) in national budgets; and technical cooperation in medical education and training.
In addition, many public-private partnerships in Africa are starting-with variable success-to expand access to medicines, health commodities, and services. This expansion includes franchising of health services, outsourcing, and cooperative arrangements for pooled procurement and distribution of medicines and other commodities. Such models may be useful, but to sustain any initial gains and reverse the continent's poor record on health and development, African institutions will need global support to track achievements; learn lessons; document success; produce and manage knowledge; and share vision and experiences.

As the leaders in the industrial world meet this week to focus on Africa and deliberate on its future, they must go beyond the traditional strategy of counting numbers and examine the critical shifts in thinking that are required to make any greater investment succeed and move the continent forward. Increasingly, that success will depend on partners being willing and able to respond to the priorities of national governments and regional institutions in Africa. The commitments are pouring in, and Africa is once again the focus of global attention. But much still needs to be accomplished.

\section{Lola Dare executive secretary}

African Council for Sustainable Health Development (ACOSHED), 29 Aare Avenue, New Bodja Estate, Ibadan, Oyo State, Nigeria (L.Dare.acoshed@yahoo.com)

\section{Eric Buch health adviser}

New Partnership for Africa's Development (NEPAD), Midrand, Pretoria, South Africa

Competing interests: None declared.

1 Unicef. The state of the world's children: childhood under threat. New York: Unicef, 2005.

2 Hecht R. Achieving the health mid decade goals-investing in health. Forum 6 , Global Forum for Health Research, 12-15 November 2002, Arusha, Tanzania [conference presentation].

3 Commission for Africa. Our common interest. London: Commission for Africa, 2005.

4 New Partnership for Africa's Development. Health strategy. Midrand: NEPAD Secretariat, 2003.

5 African Union. The Abuja Declaration on HIV/AIDS and other related infectious diseases. (At the African Summit on HIV/AIDS, TB and other related infectious diseases, Abuja 26-27 April, 2003). www.uneca.org/adf2000/ Abuja\%20Declaration.htm (accessed 27 Jun 2005).

6 African Union. Decisions and declarations. Decisions on the interim report on HIV/AIDS, tuberculosis, malaria and polio. Assembly of the African Union, 4th ordinary session, 30-31 January 2005, Abuja, Nigeria. Addis Ababa: African Union, 2005.

\title{
Stopping Africa's medical brain drain
}

\author{
The rich countries of the North must stop looting doctors and nurses from \\ developing countries
}

$\mathrm{A}$ frica will be the major focus of the G8 summit in Gleneagles next week, and rightly so. Nearly 11 million children aged under 5 years are dying every year worldwide from treatable diseases. Most of them are living in developing countries, with more than four million of these deaths in sub-Saharan Africa. ${ }^{1}$ Along with the disastrous effects of warfare, HIV/AIDS is wiping out young adults and leaving frail, malnourished children in the care of their siblings and grandparents.

It is difficult to see how the countries of sub-Saharan Africa can develop economically and politically when such large proportions of their adult populations are liv- ing with chronic diseases such as HIV/AIDS, tuberculosis, malaria, and other tropical diseases. Antiretroviral drugs could make a dramatic difference, and so could appropriate aid. Although the developed countries of the North are giving aid with one hand, they are robbing African countries with the other by siphoning off their most precious resource-trained doctors and nurses. The Commonwealth's developing countries are particularly hard hit because their health professionals speak English and are therefore a valuable commodity to plug manpower gaps in the United States, Canada, the United Kingdom, New Zealand, and Australia. 